Article

\title{
Grain Size Effect on the Hot Ductility of High-Nitrogen Austenitic Stainless Steel in the Presence of Precipitates
}

\author{
Zhenhua Wang ${ }^{1,2,3, *(\mathbb{D})}$, Yong Wang ${ }^{1}$ and Chengming Wang ${ }^{3}$ \\ 1 School of Mechanical Engineering, Yanshan University, Qinhuangdao 066004, China; \\ 528812958@stumail.ysu.edu.cn \\ 2 State Key Laboratory of Metastable Materials Science and Technology, Yanshan University, \\ Qinhuangdao 066004, China \\ 3 HBIS Group Technology Research Institute, Shijiazhuang 050023, China; wangchengming@hbisco.com \\ * Correspondence: wangzhenhua@ysu.edu.cn; Tel.: +86-3358057047
}

Received: 16 May 2018; Accepted: 13 June 2018; Published: 15 June 2018

\begin{abstract}
Precipitation occurs easily during the hot forming of high-nitrogen austenitic stainless steels, which reduces their hot ductility significantly. The effect of grain size on the hot ductility of high-nitrogen austenitic stainless steel in the presence of precipitates was investigated. Different grain sizes of $18 \mathrm{Mn} 18 \mathrm{Cr} 0.5 \mathrm{~N}$ steel specimens, with and without precipitates, were hot-tension tested. The precipitate morphology, fracture surface, and cracks were studied by scanning electron microscopy, transmission electron microscopy, and electron backscatter diffraction analysis. For the $18 \mathrm{Mn} 18 \mathrm{Cr} 0.5 \mathrm{~N}$ steel, damage-formation strains of all grain-size specimens were reduced by the precipitates during the hot-tension test. Crack-formation sites were located at grain boundaries and were independent of the Taylor factor. a larger grain size resulted in an increased sensitivity of the fracture strain to precipitates. When the grain size was smaller than $51 \mu \mathrm{m}$, the fracture strain became insensitive to the precipitates. a method was suggested to mitigate surface cracking for metal materials with a high precipitation tendency.
\end{abstract}

Keywords: high-nitrogen austenitic stainless steel; hot ductility; precipitate; grain size; damage

\section{Introduction}

In high-nitrogen austenitic stainless steels (HNASs), in excess of $0.4 \mathrm{wt} \% \mathrm{~N}$ is added to replace expensive elemental $\mathrm{Ni}$, which is usually contained in AISI 3xx series austenitic stainless steel [1]. $\mathrm{N}$ is an effective solution strengthener, an austenite stabilizer, and a corrosion-resistance enhancer [2-4]. Therefore, HNASs possess excellent mechanical, physical, and chemical properties. They are used widely in the energy, chemical, mechanical, and medical industries [5]. However, surface cracks form easily during the hot forming of HNASs, which restricts their application and development [6].

In previous studies, the influence of preheating temperature [6], strain rate [7], continuous cooling [8], grain size $[9,10]$, and delta ferrite $[11,12]$ on the hot ductility of HNASs was clarified in detail. However, these conditions differ from those encountered during the actual production of heavy-section HNAS components. In addition to the above factors, precipitates that form easily from 600 to $1050{ }^{\circ} \mathrm{C}[13,14]$ also affect the hot ductility of HNASs significantly [15]. During the hot forming of heavy-section HNAS components, where the surface may be cooled to a low temperature during forming $[8,16]$, cracks form almost simultaneously with precipitation. However, the combined effect of precipitates and other factors remains unclear. a clarification of the effect of the influencing factors on the hot ductility in the presence of precipitates would have important industrial implications. 
In this study, $18 \mathrm{Mn} 18 \mathrm{Cr} 0.5 \mathrm{~N}$ steel was selected as the model material. Specimens of different grain sizes with and without precipitates were hot-tension tested. The fracture surface, precipitate morphology, and cracks were examined. This study contributes to the development of the hot processing of HNAS components and other metal materials with a high precipitation tendency.

\section{Materials and Methods}

Commercial $18 \mathrm{Mn} 18 \mathrm{Cr} 0.5 \mathrm{~N}$ steel was melted in an induction furnace and then electroslag remelted. Its chemical composition was ( $w t \%): 0.11 \mathrm{C}, 18.46 \mathrm{Mn}, 18.5 \mathrm{Cr}, 0.54 \mathrm{~N}, 0.71 \mathrm{Si}, 0.02 \mathrm{P}$, $0.01 \mathrm{~S}, 0.01 \mathrm{Al}$, and the balance was Fe. Samples (thickness: $30 \mathrm{~mm}$; width: $30 \mathrm{~mm}$; length: $100 \mathrm{~mm}$ ) were cut from the remelted ingot and hot rolled at $1000{ }^{\circ} \mathrm{C}$ to a cumulative strain of approximately 1.6. The rolled samples were held at $1100{ }^{\circ} \mathrm{C}$ for $5 \mathrm{~min}, 1100{ }^{\circ} \mathrm{C}$ for $20 \mathrm{~min}, 1100{ }^{\circ} \mathrm{C}$ for $2 \mathrm{~h}$, and $1200{ }^{\circ} \mathrm{C}$ for $3 \mathrm{~h}$ to achieve grain sizes of $28,51,106$, and $177 \mu \mathrm{m}$, respectively. The grain morphology and grain-boundary character distribution of samples of different grain size are shown in $[10,17]$.

Samples with different grain sizes were aged at $850{ }^{\circ} \mathrm{C}$ for $30 \mathrm{~min}$ to obtain precipitates. As reported in [18], after sensitization, the relative corrosion resistances of low-angle grain boundaries, $\Sigma 3$ boundaries, and $\Sigma 9$ boundaries were $100 \%, 95 \%$, and $25 \%$, respectively; other boundaries had no resistance to corrosion. That means that $100 \%$ low-angle grain boundaries, $95 \% \Sigma 3$ boundaries, and $25 \% \Sigma 9$ boundaries are resistant to precipitation. In $177,106,51$, and $28-\mu \mathrm{m}$ specimens, the total fraction of these three special boundaries are 53.0, 53.8, 57.4, and $49.0 \%$, respectively [17]. Therefore, it is believed that grain size has no obvious effect on the fraction of grain boundary with precipitates.

Tension-test specimens (6-mm diameter $\times 120$ - $\mathrm{mm}$ length, 12-mm gage length) were cut from samples that contained precipitates. Specimens were preheated to $850{ }^{\circ} \mathrm{C}$ and then tension tested at a strain rate of $0.1 \mathrm{~s}^{-1}$ to fracture using a Gleeble 3800 simulator (Dynamic Systems Inc., Poestenkill, NY, USA). For comparison, specimens without precipitates were also tension tested under the same deformation conditions. To study the crack morphology, an additional specimen with a grain size of $177 \mu \mathrm{m}$ and that contained precipitates was tension tested to a strain of 0.27 and was not broken.

The fracture surfaces of the broken specimens were examined by scanning electron microscopy (SEM) using a Hitachi S4800 instrument. The crack morphology in the unbroken specimen was studied using electron backscatter diffraction (EBSD) analysis with TSL-OIM-Analysis software. The precipitate morphology was studied by SEM and transmission electron microscopy (TEM) using a JEM-2010 instrument (JEOL Co., Ltd., Tokyo, Japan).

\section{Results and Discussion}

\subsection{Precipitate Morphology}

Precipitates in specimens with different grain sizes were examined. The grain size had no significant effect on the precipitate morphology and distribution; precipitates were located discontinuously at grain boundaries. Figure 1 shows the typical SEM morphology of the precipitates. In Figure 1a, granular precipitates were discontinuous and located at grain boundaries. a groove or matrix existed between these particles. The groove existed because of precipitates that had been removed or because of a corroded matrix. In Figure $1 \mathrm{~b}$, the precipitates are lamellar and also discontinuous. The occurrence of precipitation at a section of the grain boundary depends on the grain-boundary type [18-20]. 

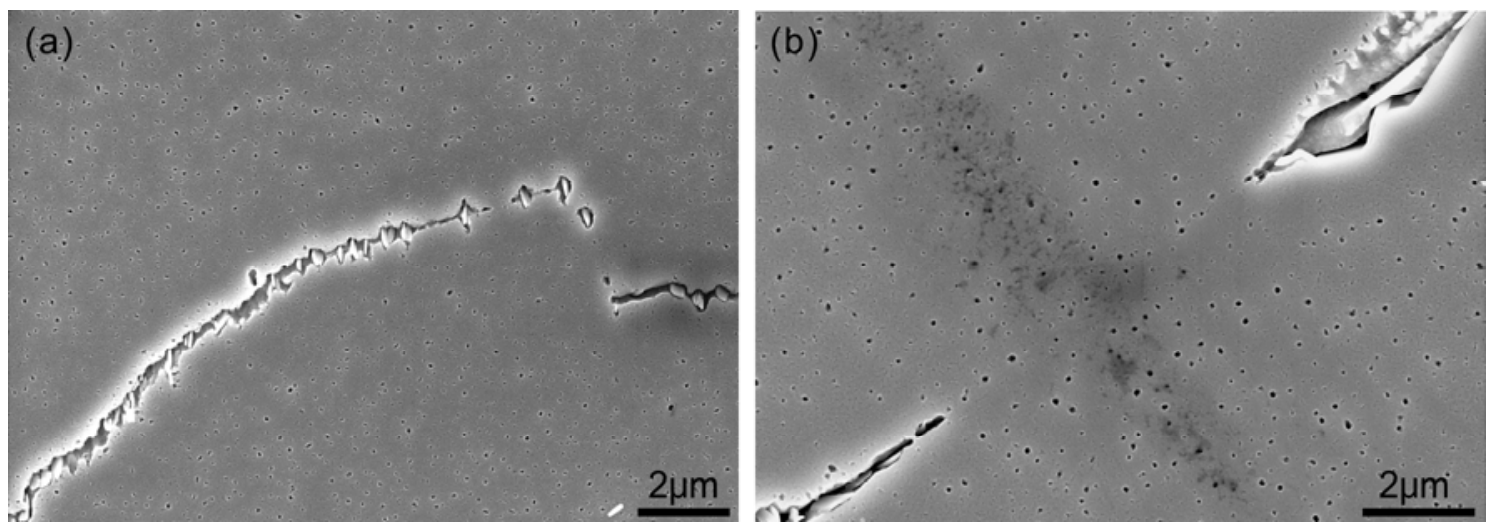

Figure 1. Typical SEM morphology of the precipitates: (a) granular and (b) lamellar.

Figure 2 shows the typical TEM morphology of the precipitates. In Figure 2a, granular precipitates form at a serrated grain boundary. Their shape and distribution indicate that during further aging, they will grow into discontinuous cellular precipitates [14,21]. Figure $2 \mathrm{~b}$ shows the TEM morphology of a lamellar precipitate; its shape is similar to the precipitate in the upper corner of Figure $2 \mathrm{~b}$.
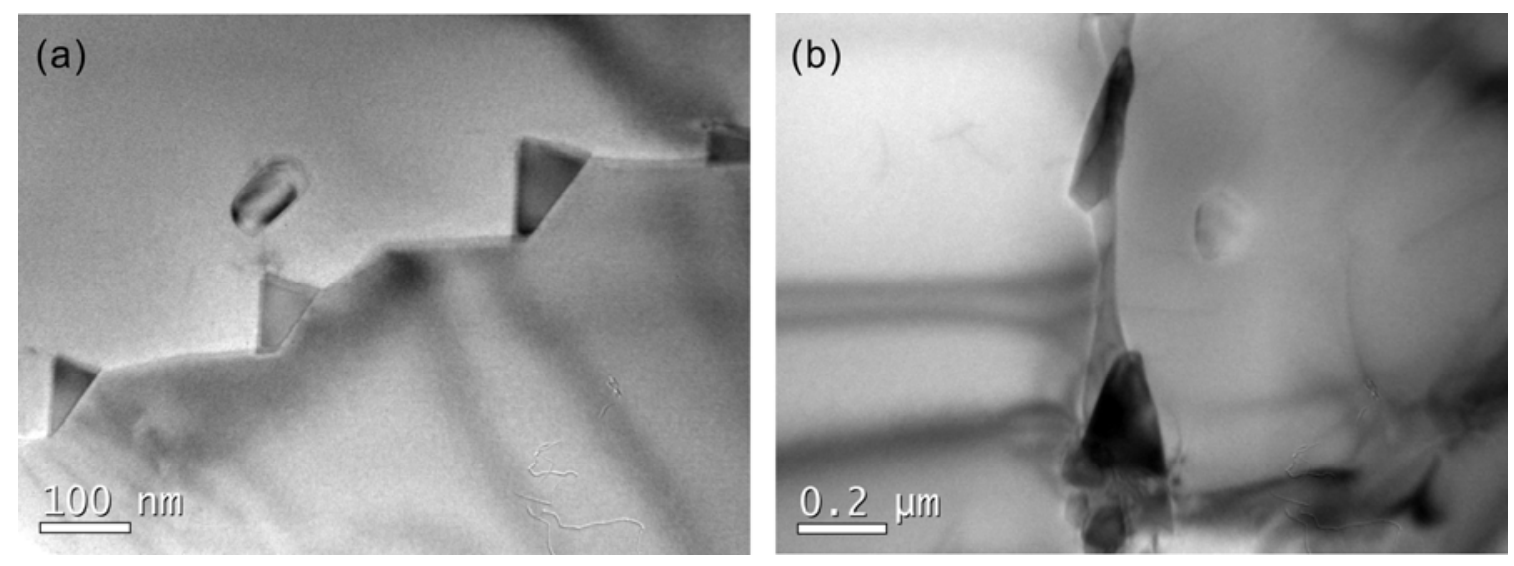

Figure 2. Typical TEM morphology of the precipitates: (a) granular and (b) lamellar.

\subsection{Flow Behaviors and Fracture Strains}

Figure 3 shows flow curves of specimens with different grain sizes. The flow curves of specimens with precipitates are represented by a red dashed line and those without by a black solid line. In Figure $3 a(177 \mu \mathrm{m})$, the flow curves of specimens with and without precipitates are almost coincident when the strain is below 0.2. Above 0.2, the strain-hardening rate is lower for the specimen with precipitates. At a strain of $\sim 0.25$, the flow stress of the specimen with precipitates decreases significantly. For the specimen without precipitates, the stress decreased at a larger strain of 0.32 . Precipitates reduce the fracture strain under this grain-size condition. In Figure $3 b(106 \mu \mathrm{m})$, the flow behaviors of specimens with and without precipitates are similar to the case in Figure $3 \mathrm{a}$. However, the difference between specimens with and without precipitates in fracture strain is smaller in Figure $1 \mathrm{~b}$ than in Figure 1a. In Figure $3 c(51 \mu \mathrm{m})$ and d $(28 \mu \mathrm{m})$, no obvious differences in flow stress and fracture strain exist between specimens with and without precipitates.

The fracture strains of specimens in Figure 3 were measured and are shown in Figure 4 . The larger grain size results in an increased fracture strain sensitivity in the presence of precipitates. When the grain size is smaller than $51 \mu \mathrm{m}$, the fracture strain of the $18 \mathrm{Mn} 18 \mathrm{Cr} 0.5 \mathrm{~N}$ steel becomes insensitive to the precipitates. 

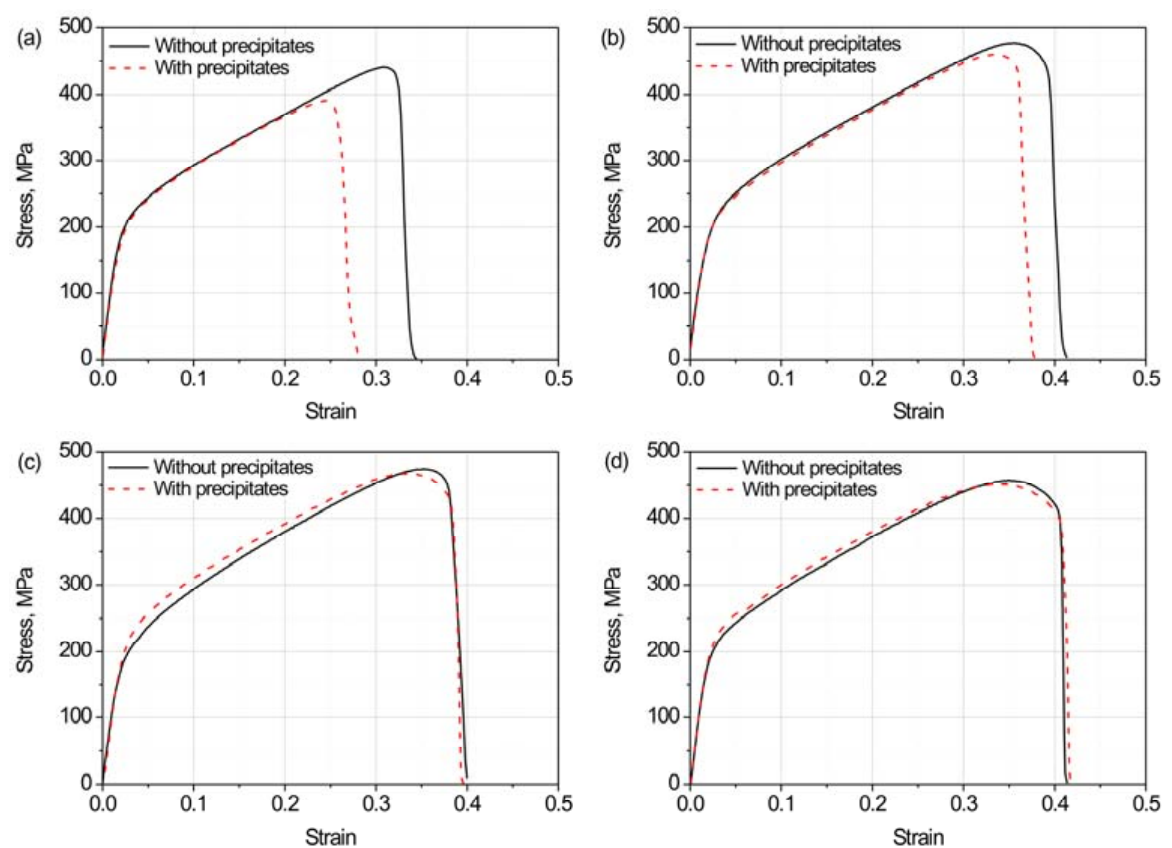

Figure 3. Flow curves of tension-tested specimens with different grain sizes $\left(850{ }^{\circ} \mathrm{C}\right)$ : (a) $177 \mu \mathrm{m}$; (b) $106 \mu \mathrm{m}$; (c) $51 \mu \mathrm{m}$; and (d) $28 \mu \mathrm{m}$.

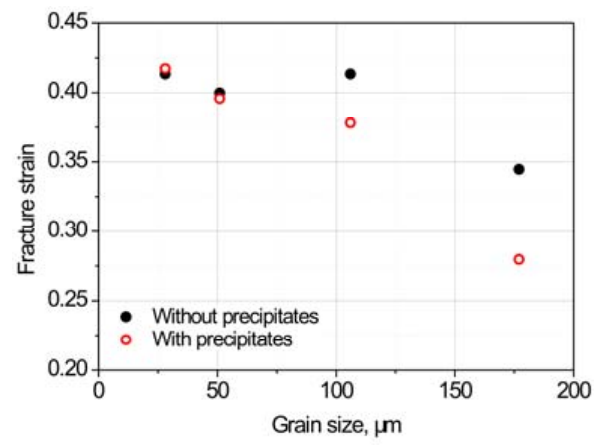

Figure 4. Fracture strains of specimens of different grain sizes with and without precipitates.

Figure 5 shows the fracture surface of the specimens with and without precipitates with a grain size of $177 \mu \mathrm{m}$. In Figure 5a (without precipitates), there is small volume fraction of ductile feature, i.e., dimples. In Figure $5 b$ (with precipitates), the fracture is almost totally brittle; flat facets and straight grain edges are found easily.
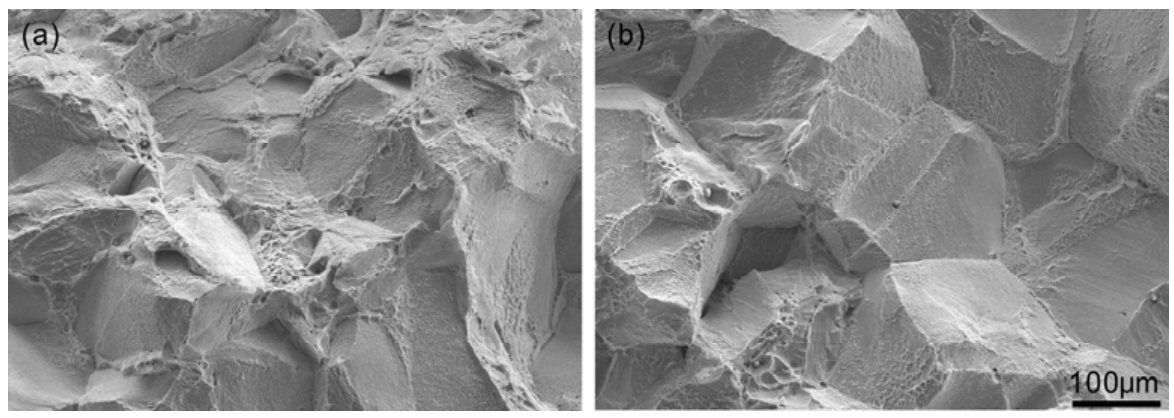

Figure 5. Fracture surface of specimens with a grain size of $177 \mu \mathrm{m}$ : (a) without precipitates (b) with precipitates. 
Figure 6 shows the fracture surface of the specimens with and without precipitates with a grain size of $51 \mu \mathrm{m}$. a large number of dimples exist in Figure 6a and b, and no flat facets or straight grain edges were observed. Figures 5 and 6 show that the fracture mechanism of large-grain-sized specimens is sensitive to the precipitates, whereas it is insensitive for fine-grained specimens. The phenomena presented in Figures 5 and 6 are consistent with those in Figures 3 and 4 and will be discussed in Section 3.3.
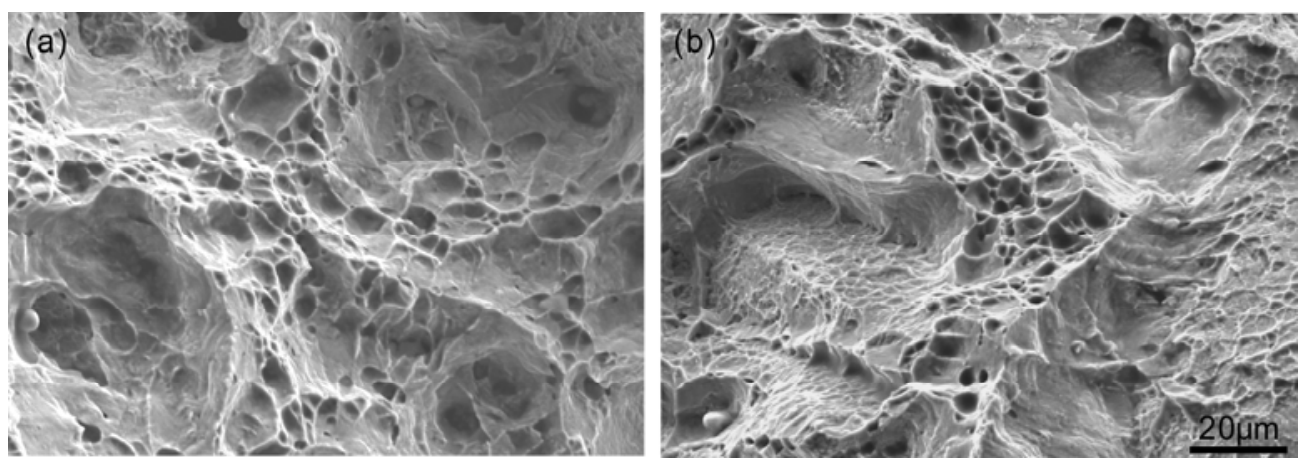

Figure 6. Fracture surface of specimens with a grain size of $51 \mu \mathrm{m}$ : (a) without precipitates and (b) with precipitates.

\subsection{Cracking and Damage Evolution}

A specimen with a grain size of $177 \mu \mathrm{m}$ and with precipitates was tension tested to a strain of 0.27. The tension tested specimen was sectioned parallel to the tensile direction to examine the cracks. In Figure 7a, cracks are marked by numbers. Small cracks, 1-8, are newly formed cracks. Large cracks, 9-11, are developed cracks. The Taylor factor is used in the analysis of the plastic deformation of polycrystalline metals and implies the distribution of the grain orientations; grains can be classified into "hard" and "soft" based on their Taylor factors [22,23]. In the Taylor factor map (Figure 7b), cracks are shaded black. Cracks 1, 3, and 10 are each located between two grains with high and low Taylor factors. Crack 2 formed between two grains with low Taylor factors. Other cracks are each located mainly between two grains with high Taylor factors. The crack-formation sites are independent of the Taylor factors in Figure 7. However, in HNAS without precipitates, cracks formed mainly between grains with high Taylor factors [10]. Obviously, precipitates reduce the grain-boundary strength. In other words, the differences between the grain inner and grain boundary in strength are pronounced in the presence of precipitates. As a result, cracks are formed easily and become insensitive to the grain orientations.
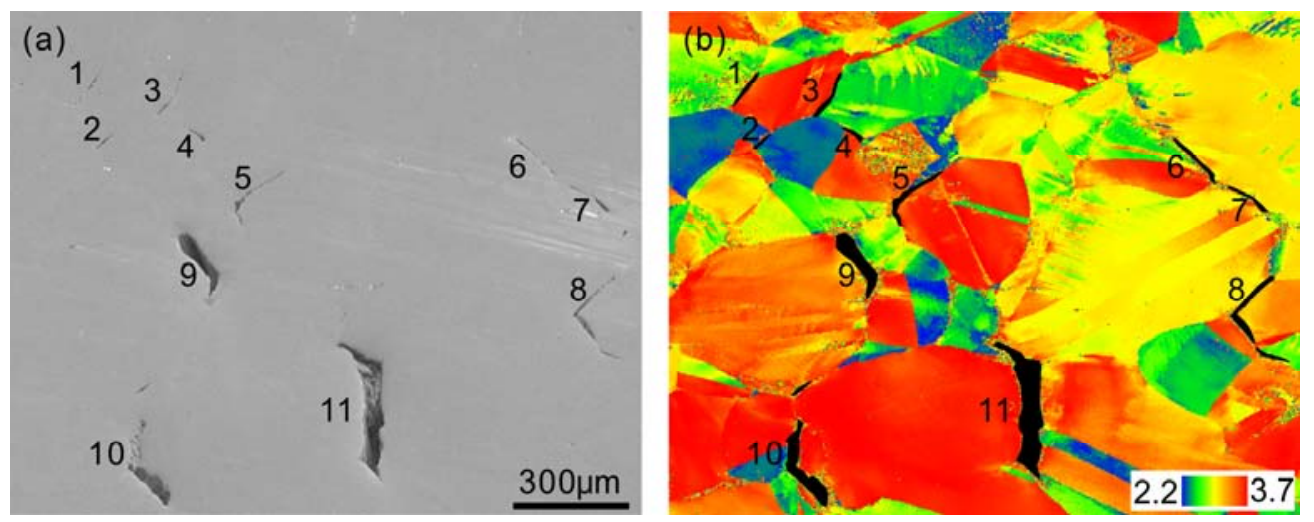

Figure 7. Morphology of cracks in a specimen with a grain size of $177 \mu \mathrm{m}$ and with precipitates tension tested to a strain of 0.27: (a) SEM map and (b) Taylor factor map. Horizontal direction is the tensile direction. 
Figure 8 shows the peak strains, i.e., the strains that correspond to the peak stresses, of specimens with different grain sizes. For all grain-size conditions, peak strains were sensitive to precipitates. During the tension test, damage such as cracks and cavities starts to form after the peak strain. The peak strain can be considered to be an initiation of damage formation. For all grain-size conditions, damage formation strains were sensitive to precipitates, which differs from the case of fracture strains that are insensitive to precipitates when the grain is smaller than $51 \mu \mathrm{m}$.

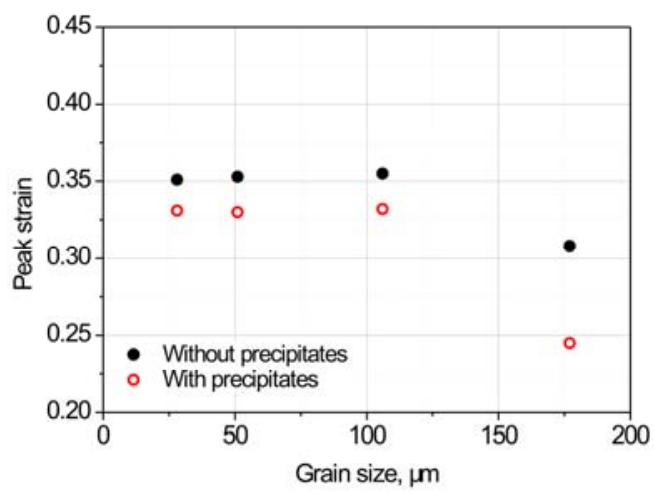

Figure 8. Peak strains of specimens of different grain sizes with and without precipitates.

The damage value at the peak strain is defined as 0 . After the peak strain, the damage value increased with an increasing strain and a decreasing stress until the specimen was broken completely, where the damage value is defined as 1 . The damage value between the peak strain and fracture strain is calculated from $1-\sigma / \sigma_{p}$, where $\sigma$ is the actual stress and $\sigma_{p}$ is the peak stress. Figure 9 shows the calculated damage values after the peak strain for specimens with precipitates during the tension tests. The growth rate of the damage value is lower in the specimen with a finer grain size. This implies that, in the presence of precipitates, a finer-grained specimen can tolerate a larger increase in strain after the peak than a larger-grained specimen.

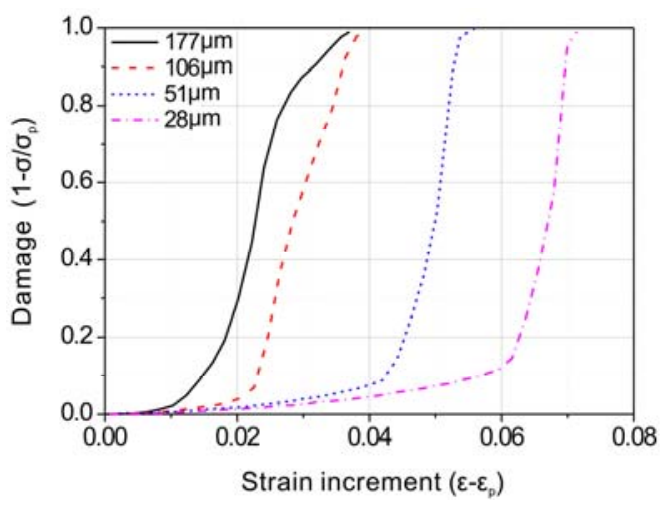

Figure 9. Damage evolution after peak strain for specimens with precipitates during tension test; $\varepsilon_{\mathrm{p}}$ is the peak strain.

Precipitates reduce the grain-boundary strength and promote cracking (Figure 7). This is consistent with previous reports that a second phase at the grain boundaries induces a stress concentration around the boundary and leads to cavity formation $[6,11,12,15]$. Therefore, the peak strain, where damage commences, is sensitive to precipitation under all grain size conditions (Figure 4).

For HNASs, precipitates were distributed discontinuously at some grain boundaries. During hot deformation, these sites with precipitates crack early. Grain-boundary segments with precipitates act as "pre-existing damage". However, grain-boundary segments without precipitates still have high 
strength in the solution-treated state. Therefore, the reason that a finer grain size promotes grain rotation and a uniform strain distribution, and enhances dynamic recrystallization [9,10], also applies when discontinuous precipitates exists. This can explain why a finer-grained specimen can tolerate a larger further strain after the peak than a larger-grained specimen in the presence of precipitates.

Based on the above results, it is suggested that, for the hot forming of heavy-section components of HNASs such as heavy retaining rings, the grain size in the ingot surface layer should be minimized as much as possible during the early hot forming stage where the surface temperature is still high and precipitation has not occurred yet. In the latter forming stage, the temperature of the ingot surface falls into the precipitation temperature range and precipitates appear. At this point, if the grain size is large, the surface cracks will develop rapidly into the inside of the ingot because a coarse grain size cannot tolerate any further strain after damage formation. In contrast, if the grain size is sufficiently small, the surface cracks remain small and do not link together; it is difficult for small surface cracks to propagate into the ingot inner during the ensuing deformation process. In addition to HNASs, many high-alloy steels and nickel alloys have a high precipitation tendency. During the hot forming of heavy-section components, the method of compressing the ingot surface quickly and lightly in the early stage of hot forming, which refines the grain size in the surface layer, can be used to mitigate surface cracking caused by precipitation.

\section{Conclusions}

For $18 \mathrm{Mn} 18 \mathrm{Cr} 0.5 \mathrm{~N}$ steel, damage-formation strains of all grain-size specimens are reduced by precipitates during hot tension tests. The crack-formation sites are located at grain boundaries and are independent of the Taylor factor. The damage growth rate is lower in specimens with a finer grain size. When the grain size is larger than $106 \mu \mathrm{m}$, precipitates reduce the fracture strain. a larger grain size results in an increased sensitivity of the fracture strain to precipitates. When the grain size is smaller than $51 \mu \mathrm{m}$, the fracture strain becomes insensitive to the precipitates. During the hot forming of heavy-section components, the method of compressing the ingot surface quickly and lightly in the early stage of hot forming can be used to mitigate surface cracking caused by precipitation.

Author Contributions: Z.W. designed the experiments, analyzed the data, and wrote the paper; Y.W. performed the microstructure examination and analysis; C.W. performed the hot tension tests and analysis.

Funding: This research received no external funding.

Acknowledgments: The authors gratefully acknowledge the financial support of the project from the National Natural Science Foundation of China (No. 51505416) and the Natural Science Foundation-Steel and Iron Foundation of Hebei Province (No. E2017203041).

Conflicts of Interest: The authors declare no conflict of interest.

\section{References}

1. Simmons, J.W. Overview: High-nitrogen alloying of stainless steels. Mater. Sci. Eng. A 1996, 207, $159-169$. [CrossRef]

2. Gavriljuk, V.G. Nitrogen in iron and steel. ISIJ Inter. 1996, 36, 738-745. [CrossRef]

3. Wang, Z.H.; Ning, X.Z.; Meng, Q.; Sun, S.H.; Fu, W.T. a new insight into manufacturing fine-grained heavy retaining rings. Mater. Des. 2016, 103, 152-159. [CrossRef]

4. Jiang, Z.H.; Feng, H.; Li, H.B.; Zhu, H.C.; Zhang, S.C.; Zhang, B.B.; Han, Y.; Zhang, T.; Xu, D.K. Relationship between microstructure and corrosion behavior of martensitic high nitrogen stainless steel 30Cr15Mn1N at different austenitizing temperatures. Materials 2017, 10, 861. [CrossRef] [PubMed]

5. Simmons, J.W. Mechanical properties of isothermally aged high-nitrogen stainless steel. Metal. Trans. A 1995, 26, 2579-2595. [CrossRef]

6. Wang, Z.H.; Fu, W.T.; Sun, S.H.; Lv, Z.Q.; Zhang, W.H. Effect of preheating temperature on surface cracking of high nitrogen CrMn austenitic stainless steel. J. Mater. Sci. Technol. 2010, 26, 798-802. [CrossRef]

7. Wang, Z.H.; Meng, Q.; Qu, M.G.; Zhou, Z.A.; Wang, B.; Fu, W.T. Effect of strain rate on hot ductility behavior of a high nitrogen Cr-Mn austenitic steel. Metall. Mater. Trans. A 2016, 47, 1268-1279. [CrossRef] 
8. Wang, Z.H.; Xue, H.P.; Fu, W.T. Fracture behavior of high-nitrogen austenitic stainless steel under continuous cooling: Physical simulation of free-surface cracking of heavy forgings. Metall. Mater. Trans. A 2018, 49, 1470-1474. [CrossRef]

9. Wang, Z.H.; Sun, S.H.; Wang, B.; Shi, Z.P.; Zhang, R.H.; Fu, W.T. Effect of grain size on dynamic recrystallization and hot-ductility behaviors in high-nitrogen CrMn austenitic stainless steel. Metall. Mater. Trans. A 2014, 45, 3631-3639. [CrossRef]

10. Wang, Z.H.; Sun, S.H.; Wang, B.; Shi, Z.P.; Fu, W.T. Importance and role of grain size in free surface cracking prediction of heavy forgings. Mater. Sci. Eng. A 2015, 625, 321-330. [CrossRef]

11. Moon, J.; Lee, T.H.; Hong, H.U. Hot ductility behaviors in the weld heat-affected zone of nitrogen-alloyed Fe-18Cr-10Mn austenitic stainless steel. Metall. Mater. Trans. A 2015, 46, 1437-1442. [CrossRef]

12. Shi, F.; Wang, L.J.; Cui, W.F.; Li, Z.B.; Xu, M.Z.; Liu, C.M. Hot ductility of Fe-18Cr-12Mn-0.55N high nitrogen austenitic stainless steel. Mater. Sci. Forum 2008, 575-578, 1056-1061. [CrossRef]

13. Knutsen, R.D.; Lang, C.I.; Bsson, J.A. Discontinuous cellular precipitation in a Cr-Mn-N steel with niobium and vanadium additions. Acta Mater. 2004, 52, 2407-2417. [CrossRef]

14. Qin, F.M.; Li, Y.J.; He, W.W.; Zhao, X.D.; Chen, H.Q. Aging precipitation behavior and its influence on mechanical properties of Mn18Cr18N austenitic stainless steel. Met. Mater. Int. 2017, 23, 1087-1096. [CrossRef]

15. Moon, J.; Lee, T.H.; Shin, J.H.; Lee, J.W. Hot working behavior of a nitrogen-alloyed Fe-18Mn-18Cr-N austenitic stainless steel. Mater. Sci. Eng. A 2014, 594, 302-308. [CrossRef]

16. Wang, Z.H.; Fu, W.T.; Sun, S.H.; Zhao, D.L.; Zhang, G.L.; Zhang, W.H.; Qv, M.G. Effect of hot deformation on the nitride precipitation behavior in high nitrogen austenitic steel. J. Mater. Eng. Perform. 2010, 19, 951-954. [CrossRef]

17. Wang, Z.H.; Qi, J.J.; Fu, W.T. The effects of initial grain size and strain on grain boundary engineering of high-nitrogen CrMn austenitic stainless steel. Inter. J. Min. Met. Mater. 2018, accepted.

18. Qi, J.J.; Huang, B.Y.; Wang, Z.H.; Ding, H.; Xi, J.L.; Fu, W.T. Dependence of corrosion resistance on grain boundary characteristics in a high nitrogen CrMn austenitic stainless steel. J. Mater. Sci. Technol. 2017, 33, 1624-1628. [CrossRef]

19. Shi, F.; Tian, P.C.; Jia, N.; Ye, Z.H.; Qi, Y.; Liu, C.M.; Li, X.W. Improving intergranular corrosion resistance in a nickel-free and manganese-bearing high-nitrogen austenitic stainless steel through grain boundary character distribution optimization. Corros. Sci. 2016, 107, 49-59. [CrossRef]

20. Yuan, X.Y.; Chen, L.Q. Effect of grain and grain boundary features on anti-corrosion ability of a high manganese austenitic TWIP steel. Acta Metall. Sin. 2016, 52, 1345-1352.

21. Lee, T.H.; Kim, S.J.; Takaki, S. Time-temperature-precipitation characteristics of high-nitrogen austenitic Fe-18Cr-18Mn-2Mo-0.9N steel. Metall. Mater. Trans. A 2006, 37, 3445-3454. [CrossRef]

22. Shen, J.H.; Li, Y.L.; Wei, Q. Stastics derivation of Taylor factors for polycrystalline metals with application to pure magnesium. Mater. Sci. Eng. A 2013, 582, 270-275. [CrossRef]

23. OIM Analysis 5.3 Manual. Available online: http://www.material.ntnu.no/ebsd/EBSD/OIM\%20Analysis\% 205_3\%20\%20Manual.pdf (accessed on 26 September 2008).

(C) 2018 by the authors. Licensee MDPI, Basel, Switzerland. This article is an open access article distributed under the terms and conditions of the Creative Commons Attribution (CC BY) license (http:// creativecommons.org/licenses/by/4.0/). 